\title{
AN INTERNATIONAL ATOMIC ENERGY LABORATORY
}

$\mathrm{T}$ HE Laboratory of the International Atomic Energy Agency at Seibersdorf, some $30 \mathrm{~km}$. from the Agency's headquarters in Vienna, which started functioning last autumn, has been designed especially for certain types of work that call for comparison and co-ordination on the widest possible basis.

Before the establishment at Seibersdorf was built, laboratory work on a small scale was done with a few facilities installed in the Agency's headquarters building. Now that adequate facilities are available, this work has considerably increased and its scope somewhat widened.

The Laboratory is not intended to be a centre of independent research; its scope is governed by the scientific requirements of the Agency's programmes of assistance to its Member States and its role in connexion with safety and security in atomic energy work. The functions of the Laboratory are thus limited to: $(a)$ measurement of radionuclides and preparation of radioactive standards; $(b)$ calibration and adaptation of measuring equipment; (c) quality control of special materials for nuclear technology; (d) measurements and analyses in connexion with the Agency's safeguards and health and safety programme; and (e) services for Member States that can be provided with the facilities established for these tasks.

In the Measurement and Standardization Section, measurements of radionuclides are being carried out by various means, including $4 \pi$ proportional counters, $\beta-\gamma$ coincidence arrangements, a $\gamma-\gamma$ coincidence arrangement and an automatic micro-calorimetric system. The Laboratory will shortly have equipment for the standardization of absorbed doses as well as sources of radiation for the calibration of instruments in terms of the absorbed dose. The Laboratory has now started a distribution service of calibrated samples of radionuclides to be used for testing and calibrating measuring instruments. The first distribution list includes 12 nuclides.

Another fundamental activity of this Section is to take part in, or to organize, intercomparison measurements of reference radioactive sources. The section will also provide practical in-service training and theoretical instruction in radioactive measure. ment and dosimetry.

In the field of radiation safety, much of the present work is related to environmental radioactivity. The analyses and measurements carried out in the Environmental Contamination Section, which are usually undertaken at the request of interested Member States, are expected also to help generally in the development of the Agency's health and safety programme. About 300 food samples, received from nine countries, have so far been analysed. At the request of the Austrian authorities, the Laboratory is conducting a continuing survey of the radioactive contamination of the most important foodstuffs in Austria.

Some scientists and technicians from six Member States have already been trained in this Section, and

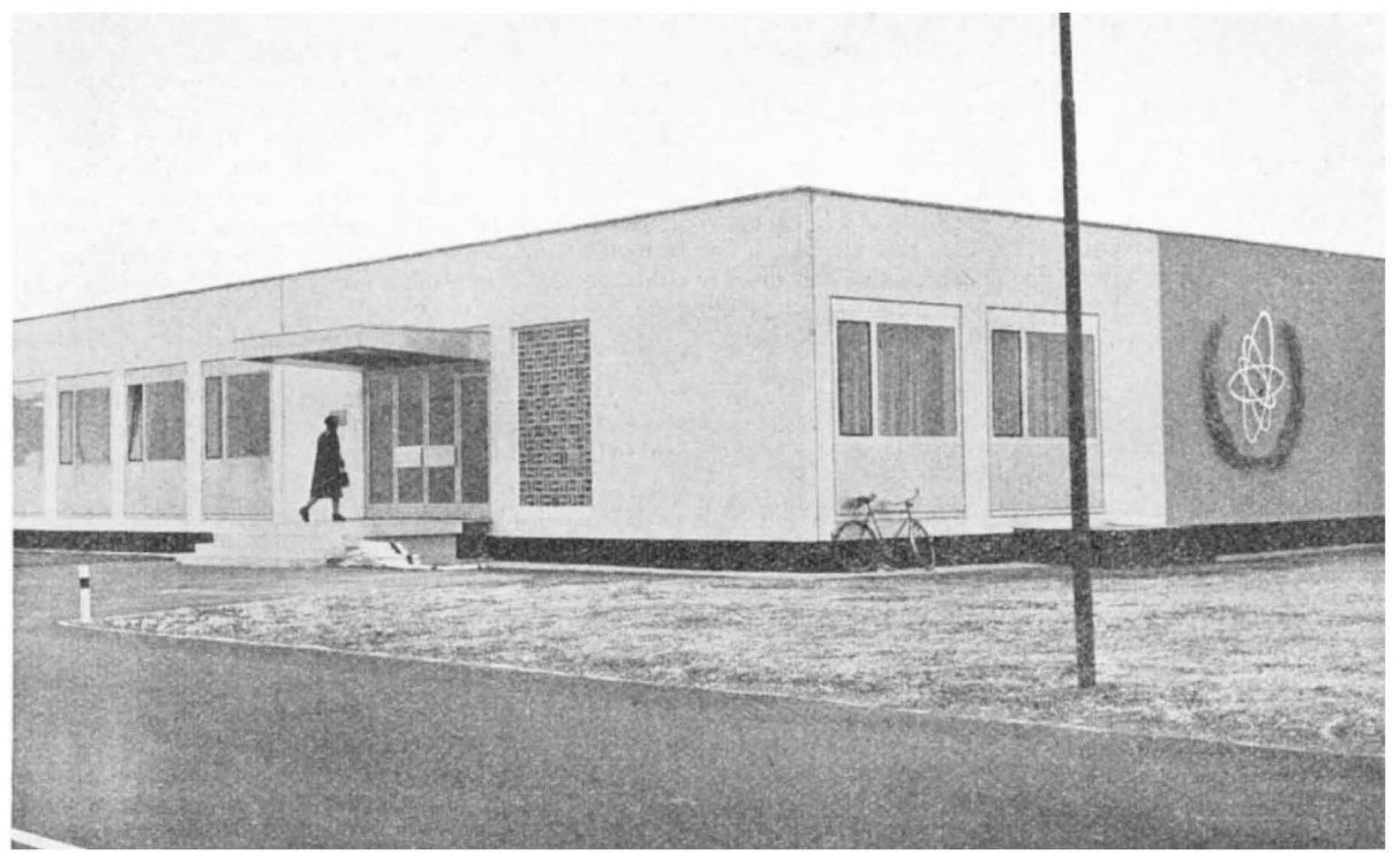

Fig. 1. Entrance to the Laboratory of the International Atomic Energy Agency at Seibersdorf, Austria 
expert advice has been provided to Member States on questions relating to environmental monitoring. Plans are also being made for a bio-assay service for radiochemical analysis of biological samples from atomic energy installations in the less-developed countries.

In the Medical and Health Physics Section, a whole-body counter is expected to be in operation from next Spring for measurements on radiation workers, at the request of Member States. The facility will also be used for the study of certain problems of immediate interest to the Agency's own work in the health physics field. For example, a study of radiation doses received by patients who have been given thorotrast for diagnostic purposes is expected to yield useful data on the late effects of small amounts of incorporated radioactivity; such data will be supplementary to those obtained by examining radium-dial painters.
The Laboratory has a well-equipped Electronics Section, which is mainly a servicing unit. A Chemistry Section is expected to be in full operation next Spring; a major part of its work will be concerned with analytical chemistry, particularly trace element analysis.

Another section of the Laboratory will deal specially with the applications of tritium in hydrology. The Agency has already started furnishing tritium laboratories in various countries with water standards in connexion with its programme for a world-wide survey of hydrogen and oxygen isotopes.

The Laboratory has its own workshop and library.

Twelve scientists from eight countries are at present employed in the Laboratory. In addition, there are 15 staff members in the general service category. The approved complement for 1962 provides for 17 professional and 28 general service staff members.

\section{RADIOBIOLOGICAL RESEARCH UNIT, HARWELL}

$\mathrm{T}$ HE Medical Research Council established its Radiobiological Research Unit at the Atomic Energy Research Establishment, Harwell, in 1947. As the name implies, its activities are devoted to the investigation of the fundamental action of ionizing radiation in living systems, and thereby to providing the solution of potential or actual problems that arise from developments in the use of nuclear energy.

By 1954 the Unit (director, Dr. J. F. Loutit) had expanded to approximately its present size, forming six interdependent sections: Experimental Pathology (Dr. R. H. Mole, now deputy director), Physiology (Dr. O. A. Trowell), Biophysics (Dr. G. J. Neary), Biochemistry (Mr. J. St. L. Philpot), Radiochemistry (Dr. G. E. Harrison) and Cytogeneties (Dr. C. E. Ford). It was then joined by a Genetics Section from Edinburgh, headed then by Dr. T. C. Carter and now by Dr. A. L. Searle.

Since it occupied its permanent quarters in 1953 , the Unit has been in the unrestricted area of the Atomic Energy Research Establishment, but on November 28, 1961, it held for the first time an open day for the Press, each section providing one or two demonstrations as an illustration of its present work.

Dr. D. Lucas (Physiology) demonstrated shortterm culture in vitro, which maintains small organs or fragments of tissue alive for several days in a chemically defined medium. This provides a means for scoring effects of radiation directly and uninfluenced by interactions in vivo. Radiosensitivity of the cells of rat lymph nodes is markedly affected by changes in oxygen tension; that of visual cells of guinea pig retina less so. This system has been used for comparing the effects of radiation and chemical toxins, and could be applied for the testing of radioprotective chemical agents.

Dr. A. L. Batchelor and Mr. F. Williamson (Biophysics) illustrated that in collaboration with the Atomic Energy Research Establishment the lowpower reactor, Gleep, had been utilized for the past ten years as a source of low-intensity fast neutrons for the chronic irradiation of populations of small animals resident therein. By comparison with cobalt-60 $\gamma$-rays, the relative biological effectiveness of these fast neutrons from uranium fission for several biological parameters was determined to be around 10. Bepo, the 6-MW. graphite-moderated natural uranium reactor, is now being adapted as a source of high-intensity fast neutrons capable of providing dose-rates of some hundreds of rads per hour in a pit of substantial size. The dosimetry of fast neutrons is effected by intercomparison of three ionization chambers, each responding primarily to fast neutrons, thermal neutrons and $\gamma$-rays: the absolute accuracy for fast neutrons is estimated as \pm 18 per cent.

Dr. H. J. Evans (also of Biophysics) reviewed the effects of radiation on the chromosomes of simple cell systems. Chromatid and chromosome breakage were shown in cells of root meristems of Vicia faba. On irradiation of Tradescantia pollen with $\gamma$-rays in atmospheres of 0-21 per cent oxygen, a remarkable increase in chromosome aberrations at low oxygen tensions was evident. With fast neutron irradiation, on the other hand, an oxygen effoct was minimal.

Dr. A. L. Searle and Dr. J. Godfrey (Genetics), having noted that most of the work on mouse radiation genetics has been concerned with mutation at specific loci, have begun to consider polygenic systems and the biological fitness of murine populations derived from an irradiated parent. Dr. Searle showed that the descendants of two sublines of $C 3 H$ exposed for 10 generations to $1 \mathrm{r}$. of $\gamma$-radiation each night showed paradoxically less divergence in certain motrical and other characters than two unirradiated sublines. On the other hand, Dr. Godfrey's offspring of irradiated mice had lower indices of fitness than comparable offspring of normal mice, the two populations being identifiable in the same common 'tenement' by a 'marker-gene'.

Dr. Jean Stanier (Biochemistry) reviewed several aspects of the work of this Section, much of which is concerned with metabolism of the cell nucleus. An airborne centrifuge has been developed for the separation of the contents of ruptured liver colls. Media 